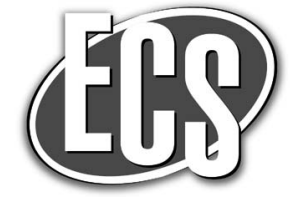

\title{
A Single-Step Monomeric Photo-Polymerization and Crosslinking via Thiol-Ene Reaction for Hydroxide Exchange Membrane Fabrication
}

\author{
Andrew C. Tibbits, ${ }^{a}$ Laura E. Mumper, ${ }^{\text {a }}$ Christopher J. Kloxin,,${ }^{a, b, z}$ and Yushan S. Yan ${ }^{a, *, z}$ \\ ${ }^{a}$ Department of Chemical and Biomolecular Engineering, University of Delaware, Newark, Delaware 19716, USA \\ ${ }^{b}$ Department of Materials Science and Engineering, University of Delaware, Newark, Delaware 19716, USA
}

A single step monomeric photo-polymerization and crosslinking via thiol-ene reaction is developed for the preparation of hydroxide exchange membranes (HEMs) in a ternary system with a triallyl triazine, a quaternary ammonium diallyl, and a dithiol. This facile method enables reproducible tuning of the ion exchange capacity and crosslink density. These HEMs demonstrate reasonable hydroxide conductivity, limited alkaline stability, and good thermal stability and have lower water uptakes than other photocrosslinked HEMs produced with much longer reaction times. Furthermore, this new fabrication method allows the incorporation of catalyst nanoparticles in the hydroxide exchange materials to form thin catalyst layers that are resistant to dissolution in methanol which suggests these polymers can be used in direct alcohol fuel cells (DAFCs).

(C) The Author(s) 2015. Published by ECS. This is an open access article distributed under the terms of the Creative Commons Attribution 4.0 License (CC BY, http://creativecommons.org/licenses/by/4.0/), which permits unrestricted reuse of the work in any medium, provided the original work is properly cited. [DOI: 10.1149/2.0321510jes] All rights reserved.

Manuscript submitted June 1, 2015; revised manuscript received July 9, 2015. Published July 31, 2015.

Hydroxide exchange membrane fuel cells (HEMFCs) have the potential to decrease the overall fuel cell system cost through the utilization of non-precious metal catalysts (e.g., nickel) and inexpensive bipolar plates (e.g., aluminum). ${ }^{1}$ As one of the key components for a HEMFC, the hydroxide exchange membrane (HEM) has to be both reasonably ion conductive and have low water uptake (WU). Attempts to increase ion conductivity in HEMs typically lead to increased water uptake and excessive swelling that, in the extreme cases, results in the dissolution of the membrane. Covalent crosslinking of the polymeric HEM is an approach that effectively combats excessive swelling and dissolution that would otherwise occur during fuel cell operation., ${ }^{2,3}$ Typically, polymer crosslinking methods for HEM fabrication require separate polymerization and crosslinking steps necessitating careful manipulation of reaction conditions including the reaction time, reactant concentrations, and temperature. As a result of this complexity, the reproducible fabrication of cross-linked HEMs is still an ongoing challenge in the development of fuel cell membranes to achieve consistent ion exchange capacities (IECs) and degrees of crosslinking (DC).

Several groups have already demonstrated that a single-step polymerization and crosslinking fabrication of HEMs is possible using photo-polymerization, ${ }^{4-8}$ thermal polymerization, ${ }^{9}$ and ring opening metathesis polymerization (ROMP). ${ }^{10,11}$ A single-step polymerization and crosslinking reaction enables precise control over the degrees of functionalization (and thus IEC) and crosslinking imparted by the use of small molecules rather than large polymer precursors. Moreover, photo-crosslinking, which allows for rapid initiation and propagation, has been demonstrated by numerous groups in the formation of solvent-resistant networks ${ }^{4-8,12-14}$ and is a particularly attractive means to fabricate membranes because of the low cost, safety, and spatial-temporal control afforded by the use of light initiation.

Thus far, all of the studies involving the photo-copolymerization and crosslinking reaction between vinyl-functionalized comonomers have proceeded under traditional free-radical mechanisms which consequently have limited the functional group conversions. Thiol-ene 'click' chemistry entails the facile reaction between a thiol (an -SH group) and an ene (an electron rich double bond, $\mathrm{C}=\mathrm{C}$ ) in the presence of photo-initiator and light. ${ }^{15,16}$ These organic reactions have been shown to be rapid, high yielding (quantitative conversions), selective, and able to proceed under ambient conditions in the fabrication of polymer networks. ${ }^{15-17}$ While thiol-ene chemistry has been used to fabricate HEMs via crosslinking of polymer chains, ${ }^{12-14}$ it has not been employed for the preparation of HEMs via the single-step photo-

\footnotetext{
*Electrochemical Society Active Member.
}

zE-mail: cjk@udel.edu; yanys@udel.edu. polymerization and crosslinking of monomers. Here, we report for the first time a single-step photo-initiated polymerization and crosslinking of thiol-ene-based charged monomers to rapidly design and fabricate HEMs for fuel cell applications.

One significant advantage of implementing photo-initiated thiolene chemistry to fabricate HEMs is the large number of commercially available monomers including charged candidates that possess thiol and ene functional groups. For example, there are a number of allylic ionic liquids that could act as a pendent, additive charge to the polymer network. In this report, we have selected diallyldimethylammonium chloride (DADMAC), 1,3,5-triallyl-1,3,5-triazine-2,4,6 $(1 \mathrm{H}, 3 \mathrm{H}, 5 \mathrm{H})$ trione (TATATO) and 1,6-hexanedithiol (HDT) as the charged monomer, the crosslinker, and the dithiol comonomer, respectively.

\section{Experimental}

Materials. - Diallyldimethylammonium chloride (DADMAC) ( $\geq 97.0 \%$ ), triallyl-1,3,5-triazine-2,4,6-trione (TATATO) (98\%), and 1,6-hexanedithiol (HDT) $(\geq 97.0 \%)$ were purchased from SigmaAldrich and used as-received. The photo-initator, Irgacure 651 (I651), was procured from BASF (Ciba). Tokuyama AS-4 ionomer (5 wt\% in n-propanol) and Tokuyama A201 membranes were purchased directly from Tokuyama America. Tokuyama AS-4 ionomer was used as-received and Tokuyama A201 was immersed in $1 \mathrm{M} \mathrm{KOH}$ for 48 hours prior to use to ensure the membrane was in hydroxide form. Vulcan XC-72 carbon black was purchased from Cabot.

Synthetic method formembranes and catalyst layers. - The singlestep photo-polymerization and crosslinking synthesis scheme for the thin film membranes is depicted in Figure 1. To prepare the membranes, appropriate molar quantities of DADMAC, TATATO, and HDT were mixed in scintillation vials with $1.5 \mathrm{wt} \%$ I651. Dimethyl sulfoxide (DMSO) was then added to solubilize all components such that the solution contained 1 M DADMAC. 1:1 stoichiometry of the total thiols and enes in each sample was maintained while the mole fraction of enes contributed from DADMAC was varied to tune both the crosslink density and IEC for the photo-crosslinked HEMs.

Each solution was injected into a custom-made apparatus consisting of two glass microscope slides separated by matte shims $(191 \mu \mathrm{m})$ which were selected to synthesize membranes between 100-150 $\mu \mathrm{m}$ in thickness. Irradiation was then carried out using $365 \mathrm{~nm}$ filtered light from a UV lamp at $80 \mathrm{~W} / \mathrm{m}^{2}$ for 10 minutes. After the photocrosslinking reaction was completed, the fabricated membranes were thermally dried at $60^{\circ} \mathrm{C}$ for 36 hours to remove DMSO. The membranes were each subsequently immersed in $1 \mathrm{M} \mathrm{KOH}$ for 48 hours to ensure complete ion exchange from chloride to hydroxide form and 

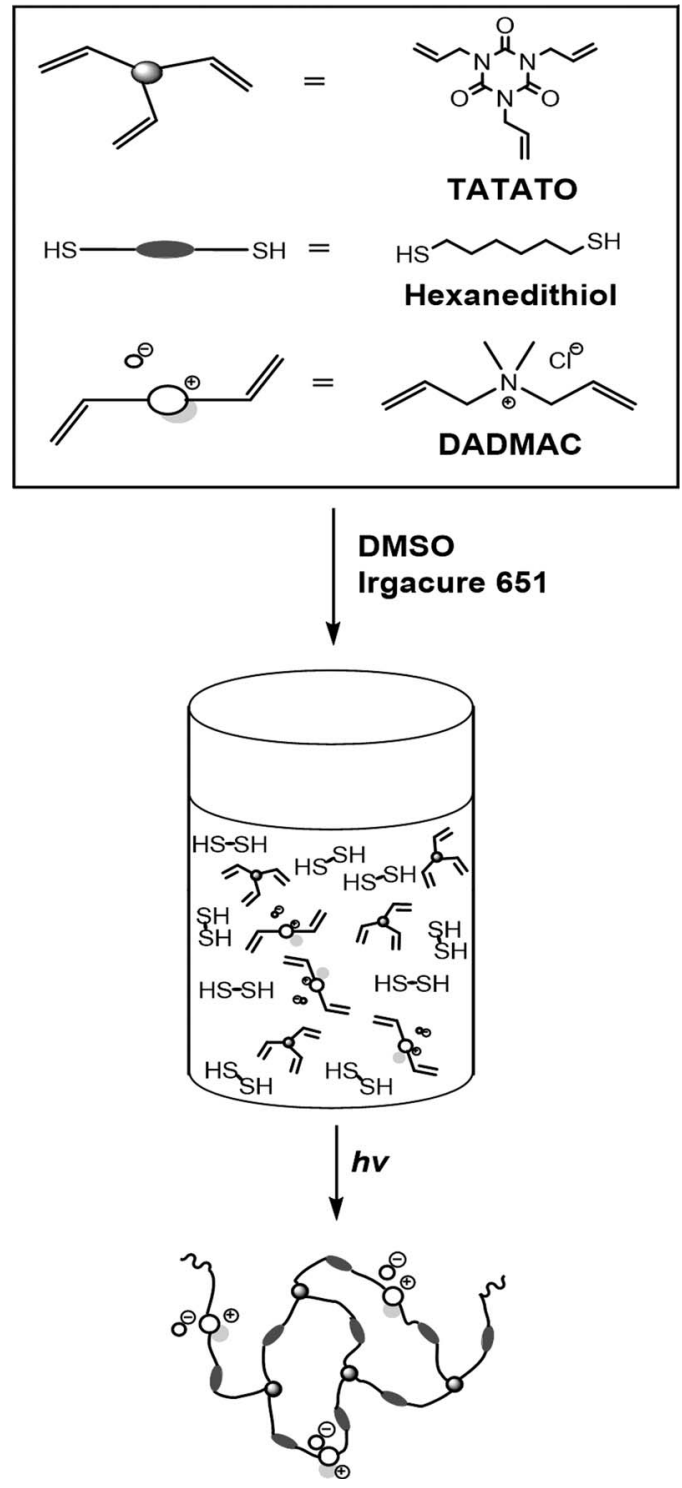

Figure 1. Overview of hydroxide exchange membrane synthesis. A triallyl crosslinker, TATATO, an ionic liquid imparting system charge, DADMAC (1 $\mathrm{M}$ in solvent), and a dithiol linker, HDT, are dissolved with photo-initiator Irgacure 651 (I651) in dimethyl sulfoxide (DMSO) and irradiated with filtered UV light $(365 \mathrm{~nm})$ to polymerize and crosslink monomers into HEMs in a single step.

then were thoroughly washed and immersed in deionized water for a minimum of 24 hours prior to any testing. All deionized water used for membrane washing and testing was first purged with Argon to ensure membranes were not converted to bicarbonate form.

A similar synthetic scheme as that shown in Figure 1 was used to fabricate photo-crosslinked thin film catalyst layers. Since the goal was to test the alcohol resistance of the polymer in the context of being used as an ionomer in a catalyst layer, the catalyst ink was prepared by mixing Vulcan XC-72 carbon black (not Pt/C) with the monomer solution such that the concentration of DADMAC in DMSO was $1 \mathrm{M}$ and then sonicating for 1 hour. The mass ratio of monomers (DADMAC, TATATO, and HDT) to Vulcan XC-72 was 10:1 and was selected to prevent significant aggregation of carbon black nanoparticles in solution, to minimize attenuation of light during irradiation, and to make it easier to test the alcohol resistance of the polymer. The ink was subsequently injected between two glass slides, irradiated, and dried under identical conditions as the photo-crosslinked HEM. The photocrosslinked thin film catalyst layer was then carefully peeled from the glass slide prior to testing. Tokuyama AS-4 ink was prepared by adding $500 \mathrm{mg}$ Tokuyama AS-4 (hence $25 \mathrm{mg}$ ionomer) and $250 \mathrm{mg}$ carbon black to $1.8 \mathrm{~mL}$ DMSO, sonicating for 1 hour, and then dropcasting onto glass slides prior to drying at $60^{\circ} \mathrm{C}$ for 36 hours. The resultant film was peeled carefully from the glass slide prior to testing.

Membrane characterization.- The IECs of the HEMs were measured using a back titration method. The membranes in chloride form (approximately $0.5 \mathrm{~g}$ samples) were immersed in $1 \mathrm{M} \mathrm{KOH}$ for 48 hours for ion exchange to hydroxide form. They were then washed and immersed in $30 \mathrm{~mL}$ of $0.1 \mathrm{M} \mathrm{HCl}$ for 24 hours. Phenolphthalein indicator was added to the solutions which were titrated with a $\mathrm{NaOH}$ standard solution and the volume recorded. A blank control sample of $30 \mathrm{~mL}$ of $0.1 \mathrm{M} \mathrm{HCl}$ was also titrated with $\mathrm{NaOH}$ standard solution and the difference between the volume required to titrate the control and the sample with membrane was used to compute the number of hydroxide ions in the membranes. Subsequently, the membranes were immersed in $1 \mathrm{M} \mathrm{HCl}$ to ensure conversion into chloride form and then dried at $60^{\circ} \mathrm{C}$ for 24 hours to obtain the dry mass of the chloride form membrane $\left(m_{\text {chloride form }}\right)$. The IEC was then computed using the formula:

$$
I E C=\frac{\text { mmol of hydroxide ions in membrane }}{m_{\text {chloride form }}}
$$

Each IEC measurement was taken at least 3 times to ensure reproducibility of results.

The alkaline stability of HEMs was determined by measuring the IEC after immersion in concentrated $(5 \mathrm{M}) \mathrm{KOH}$ for 1 week and 2 weeks at room temperature.

Hydroxide conductivity was determined in the longitudinal direction using a four-electrode AC impedance technique at constant current with an amplitude of $0.005 \mathrm{~mA}$ to measure membrane resistivity over a frequency range from $1 \mathrm{~Hz}$ to $100 \mathrm{kHz}$ to generate Nyquist plots. An impedance/gainphase analyzer (Solartron SI 1260) and a potentiostat (Solartron SI 1287) were used to measure the current between the working and counter electrodes and sense the potential drop between the platinum wire reference electrodes. All membranes were immersed in Argon-purged deionized water for 24 hours prior to testing.

$$
\sigma=\frac{L}{W d R}
$$

The hydroxide conductivity in $\mathrm{mS} / \mathrm{cm}$ is denoted by $\sigma, W$ is the width of the membrane $(\mathrm{cm}), d$ is the thickness of the membrane $(\mu \mathrm{m}), R$ is the membrane resistance determined from the right-side intersect of the Nyquist plot with the real axis $(\mathrm{m} \Omega)$, and $\mathrm{L}$ is the distance between the two reference electrodes $(\mu \mathrm{m})$.

Water uptake, $W U$, of the membranes (in hydroxide form) was determined using the formula below:

$$
W U=\frac{m_{w e t}-m_{d r y}}{m_{d r y}} * 100 \%
$$

After immersion in 24 hours, surface water was quickly blotted from the membrane and subsequently the wet mass $\left(m_{\text {wet }}\right)$ was measured and recorded. The membranes were dried in the oven at $60^{\circ} \mathrm{C}$ for 24 hours prior to recording the dry mass $\left(m_{d r y}\right)$.

Methanol permeability experiments were completed using a twochamber glass cell procured from Adams and Chittenden with a membrane separator cross-sectional area of $4.52 \mathrm{~cm}^{2}$. After securing the hydroxide form membranes in place, $100 \mathrm{~mL}$ of $1 \mathrm{M}$ aqueous methanol was poured into the left chamber and $100 \mathrm{~mL}$ of deionized water was poured into the right chamber. $0.2 \mathrm{vol} \%$ 1-butanol was also added to each chamber to be used as an internal standard and both reservoirs were stirred with a magnetic stir bar. Agilent Gas Chromatograph Series 6890A equipped with an HP-Plot Q column and a flame ionization detector (FID) was used to analyze the concentrations of methanol over time via $1 \mu \mathrm{L}$ direct injections of aqueous solution from the right chamber every hour. The concentration of methanol at each time was 
determined by integrating the peak area relative to the internal standard and comparing to the produced calibration curve. The equation below was linearly fit to the data to determine the membrane methanol permeability $(\mathrm{P})$ in $\mathrm{cm}^{2} / \mathrm{s}^{18,19}$

$$
C_{B}(t)=\frac{A P C_{A}}{L V_{B}}\left(t-t_{0}\right)
$$

In the above expression, $A$ is the membrane effective cross-sectional area $\left(\mathrm{cm}^{2}\right), L$ is the membrane thickness $(\mu \mathrm{m}), C_{A}$ is the concentration of methanol in the left chamber (assumed constant at $1 \mathrm{M}$ ), $C_{B}(t)$ is the time-dependent concentration of methanol in the right chamber $(M)$, $V_{B}$ is the volume of solution in the right chamber (assumed constant at $100 \mathrm{~mL}$ ), $t$ is the elapsed time in seconds, and $t_{0}$ is the time lag in seconds.

A Thermo Nicolet Nexus 670 Fourier transform infrared (FTIR) Spectrometer equipped with a deuterated triglycine sulfate (DTGS) detector was used to measure the conversion of the thiols and enes from $4000-400 \mathrm{~cm}^{-1}$. An AVIII $600 \mathrm{MHz}$ nuclear magnetic resonance (NMR) spectrometer was used for supplementary studies of ene reactivity. TA Instruments dynamic mechanical analyzer (DMA) Q800 in tensile mode was used for the determination of the mechanical properties of the chloride form membranes, specifically the elastic moduli. Scanning electron microscopy (SEM) images were taken from JSM 7400F microscope equipped with X-ray dispersive spectroscopy (EDX) capabilities using a secondary electron imaging (SEI) detector. An accelerating voltage of $3 \mathrm{eV}$ was used for SEM images and an accelerating voltage of $6 \mathrm{eV}$ was used for EDX analyses. Thermal stability of membranes was determined using a Mettler Toledo TGA/DSC thermal gravimetric analyzer with STARe System Software over a temperature range of $30^{\circ} \mathrm{C}$ to $300^{\circ} \mathrm{C}$ under $80 \mathrm{~mL} / \mathrm{min}$ $\mathrm{N}_{2}$ flow with a temperature ramp rate of $5{ }^{\circ} \mathrm{C} / \mathrm{min}$ after initial drying of membranes at $60{ }^{\circ} \mathrm{C}$ for 24 hours.

\section{Results and Discussion}

Completion of the photo-initiated thiol-ene reaction. - The thiolene reaction proceeds via a radical-mediated addition reaction between thiol and ene functional groups. This copolymerization is indeed a chain reaction (i.e., one generated radical species leads to multiple reaction events), but does not follow a chain-growth mechanism where one radical leads to homopolymerization of the vinyl species. A signature of this alternating thiol-ene copolymerization is the complete conversion of thiol and ene functional groups.

FTIR was used to monitor the disappearance of the thiol and ene groups as a function of irradiation time to verify that all functional groups proceed to full conversion. Although all samples were irradiated for 10 minutes, FTIR revealed that the thiol and ene functional groups in all the monomer systems went to complete conversion within 1 minute as indicated by the disappearance of the thiol and ene peaks at $2500 \mathrm{~cm}^{-1}$ and $3060 \mathrm{~cm}^{-1}$, respectively (see Figure 2). These are the characteristic absorptions of the $\mathrm{S}-\mathrm{H}$ and $=\mathrm{C}-\mathrm{H}$ (alpha hydrogens to the alkene) stretching modes of the monomers, which is consistent with the literature. ${ }^{20}$ Additionally, we irradiated a sample of DADMAC dissolved in DMSO with $1.5 \mathrm{wt} \%$ photo-initiator (I651), revealing negligible chain-growth homopolymerization (see ${ }^{1} \mathrm{H}$ NMR data in Figure 3). Overall, these results indicate that the only significant reaction occurring in our system is the thiol-ene copolymerization as opposed to homopolymerization of the allylic functional groups.

Tunable control over ion exchange capacity and crosslink density. - To highlight the enhanced tunability of HEM properties with varying comonomer stoichiometry, the membrane IEC and crosslink density $\left(\rho_{x}\right.$ with units $\left.\mathrm{mol} / \mathrm{cm}^{3}\right)$ of several membrane formulations were measured in the dry-state (i.e., in absence of solvent effects). Rubber elasticity theory ${ }^{21}$ states that the crosslink density scales as the elastic modulus $(E)$ of a fully crosslinked polymer network as

$$
E \sim \rho_{x} R T,
$$

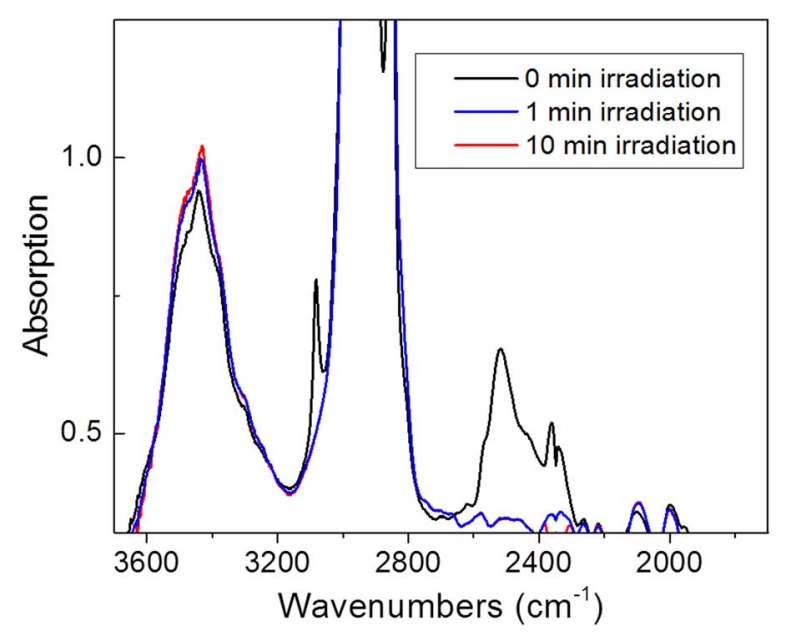

Figure 2. FTIR spectra of DADMAC membranes showing full conversion of thiol $\left(2500 \mathrm{~cm}^{-1}\right)$ and ene $\left(3060 \mathrm{~cm}^{-1}\right)$ functional groups after 1 and 10 minutes irradiation of $365 \mathrm{~nm}$ UV light at $80 \mathrm{~W} / \mathrm{m}^{2}$ for DADMAC enes mole fraction 0.303. All spectra are identical for the membrane formulations tested.

where $T$ is the absolute temperature and $R$ is the gas constant. This relationship enables one to infer differences in crosslink density by examining differences in moduli between each membrane formulation.

Figure 4 reveals that the IEC is positively correlated with the DADMAC mole fraction. This is the expected relationship since increasing the DADMAC component within the formulation effectively increases the charge within the membrane. Conversely, the elastic modulus decreases with increasing DADMAC mole ratio. This follows from the fact that increasing DADMAC necessitates a decrease in the crosslinker (i.e., TATATO) to preserve the thiol and ene stoichiometric balance. Furthermore, the relatively small error associated with each measurement indicates that the membrane properties are reproducible for a given formulation. By simply adjusting the comonomer

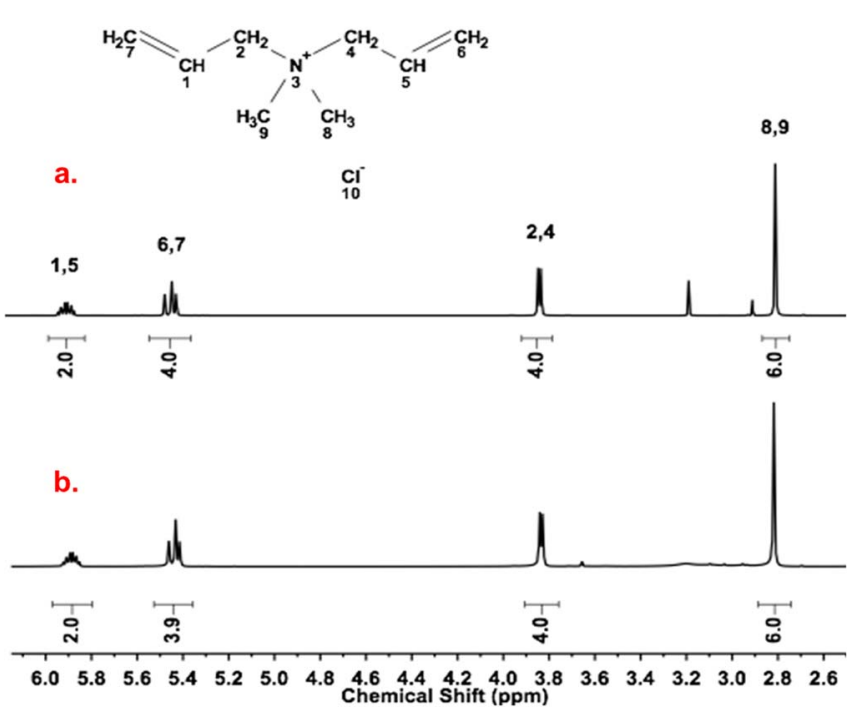

Figure 3. ${ }^{1} \mathrm{H}$ NMR spectra of DADMAC (1 M in d-DMSO) with $1.5 \mathrm{wt} \%$ I651 photo-initiator both prior to irradiation and after 10 minutes of irradiation. These spectra show little change in the ene peak area at $5.43 \mathrm{ppm}$ suggesting that the thiol-ene reaction is the predominant reaction occurring rather than DADMAC homopolymerization. The non-labelled peaks correspond to the photo-initiator. (a) ${ }^{1} \mathrm{H}$ NMR of DADMAC in deuterated DMSO with $1.5 \mathrm{wt} \%$ I651 pre-irradiation. (b) ${ }^{1} \mathrm{H}$ NMR of DADMAC in deuterated DMSO with $1.5 \mathrm{wt} \%$ I651 after 10 minutes irradiation. 


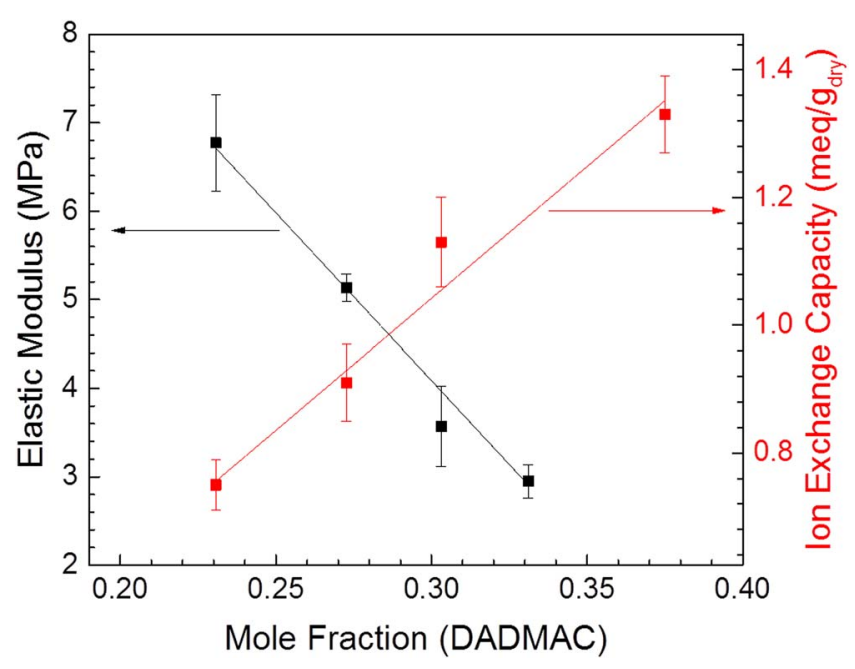

Figure 4. Linear fitting of elastic modulus and ion exchange capacity to mole fraction of DADMAC. The linear fits were computed using Origin 9.1 software and demonstrate the facile tunability of membrane properties via alteration of comonomer stoichiometry.

stoichiometry in the formulation, the IEC and elastic moduli of the DADMAC-based HEMs are readily tuned.

Properties as a hydroxide exchange membrane.- As previously mentioned, the hydroxide conductivity and water uptake of HEMs are critical parameters in the design and operation of a fuel cell. Figure 5 shows that the water uptake for these membranes is very low as expected for covalently crosslinked membranes. At larger IEC values and a correspondingly lower crosslink density, the water uptake exponentially increases, resulting in swelling values beyond what would be permissible in fuel cell applications.

The hydroxide conductivity increases with increasing IEC until reaching an IEC value of $1.13 \mathrm{meq} / \mathrm{g}_{\text {dry }}$. This effect likely owes to the dilution of the ion exchange functional groups beyond certain water uptake, which is commonly observed in other HEMs. ${ }^{22}$ This hypothesis is further supported by the water solvation number, $\lambda$, which is the number of water molecules per quaternary ammonium ion conductive group and is determined for polymer fuel cell membranes using ${ }^{23,24}$

$$
\lambda=\frac{W U}{I E C * M_{\mathrm{H}_{2} \mathrm{O}}},
$$

where $W U$ is the water uptake as previously defined and $M_{\mathrm{H}_{2} \mathrm{O}}$ is the molecular weight of water. The water solvation number, $\lambda$, is 19.6 and 33.9 for the membranes possessing an IEC of 1.13 and $1.33 \mathrm{meq} / \mathrm{g}_{\mathrm{dry}}$, respectively. Even at a modest increase in IEC, the water solvation number nearly doubles, suggesting an increase in the number of water molecules relative to the number of quaternary ammonium groups and resulting in the dilution of the conductive sites. Therefore, the DADMAC-based HEM with an IEC of $1.13 \mathrm{meq} / \mathrm{g}_{\text {dry }}$ is estimated to be the peak hydroxide conductivity without a significant compromise in solvent uptake, making this formulation the optimal for the photopolymerized and crosslinked HEMs.

The alkaline stability and thermal stability of the DADMAC-based membranes (IEC of $1.13 \mathrm{meq} / \mathrm{g}_{\text {dry }}$ ) are shown in Table I and Figure 6, respectively. Despite the $25 \%$ loss in IEC after two weeks, the membranes still maintained their flexibility suggesting that the decrease in IEC came from the instability of the ammonium groups rather than the network backbone. The typically poor dimensional stability of membranes in alcohol and the high permeability of liquid fuels in direct alcohol fuel cells (DAFCs) pose another challenge in the design of HEMs. ${ }^{25}$ However, the membranes in this study exhibit a low methanol permeability $\left(3.75 \times 10^{-7} \mathrm{~cm}^{2} / \mathrm{min}\right)$ and a low methanol uptake of $51 \%$ (slightly higher than the water uptake, $39.9 \%$ ), sug-

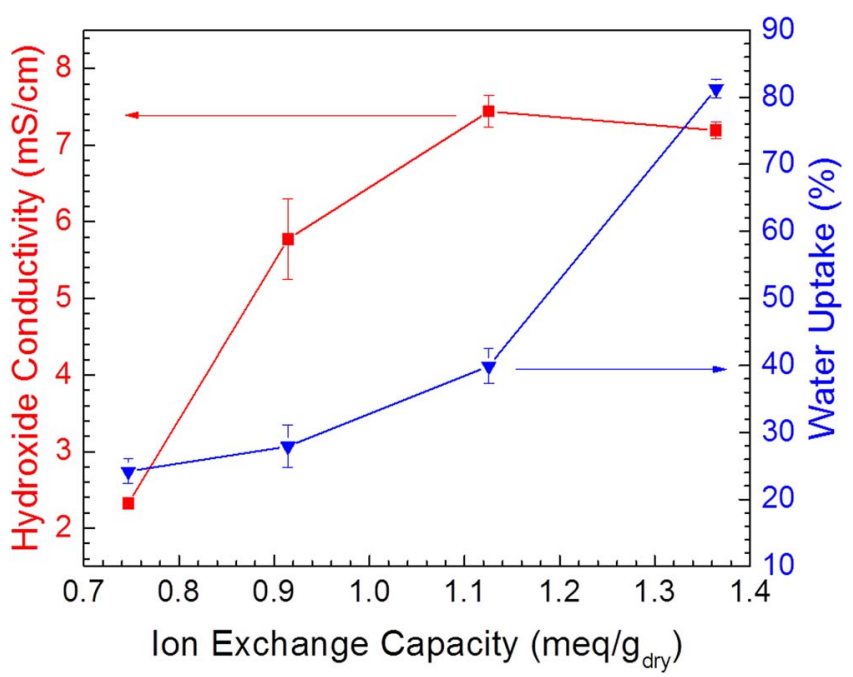

Figure 5. Hydroxide conductivity (left axis) and water uptake (right axis) of photo-crosslinked DADMAC HEMs as a function of measured ion exchange capacity. All membranes were characterized in hydroxide form and were between $100-150 \mu \mathrm{m}$ in thickness.

\section{Table I. Chemical stability of DADMAC-based HEM after immersion in $5 \mathrm{M} \mathrm{KOH}$ for 1 and 2 weeks}

\begin{tabular}{cccc} 
Membrane & $\begin{array}{c}\text { IEC (initial) } \\
\left(\mathrm{meq} / \mathrm{g}_{\mathrm{dry}}\right)\end{array}$ & $\begin{array}{c}\text { Percent IEC } \\
\text { Remaining } \\
(1 \text { week })\end{array}$ & $\begin{array}{c}\text { Percent IEC } \\
\text { Remaining } \\
(2 \text { weeks })\end{array}$ \\
\hline $\begin{array}{c}\text { DADMAC-based } \\
\text { HEM }\end{array}$ & 1.13 & $94 \%$ & $75 \%$
\end{tabular}

gesting that these DADMAC-based materials may also be appropriate for DAFC applications.

Table II summarizes the properties of all photo-crosslinked HEMs for fuel cell applications presently found in the literature. The only other photo-crosslinked HEMs synthesized via thiol-ene chemistry have been reported by Stoica et al., ${ }^{12}$ Sollogoub et al., ${ }^{13}$ and Vandiver et al. ${ }^{14}$ The others were polymerized and crosslinked using traditional free-radical, chain-growth mechanisms. Thiol-ene photopolymerization reactions proceed through a rapid radical mechanism, but the molecular weight builds through a step-growth mechanism,

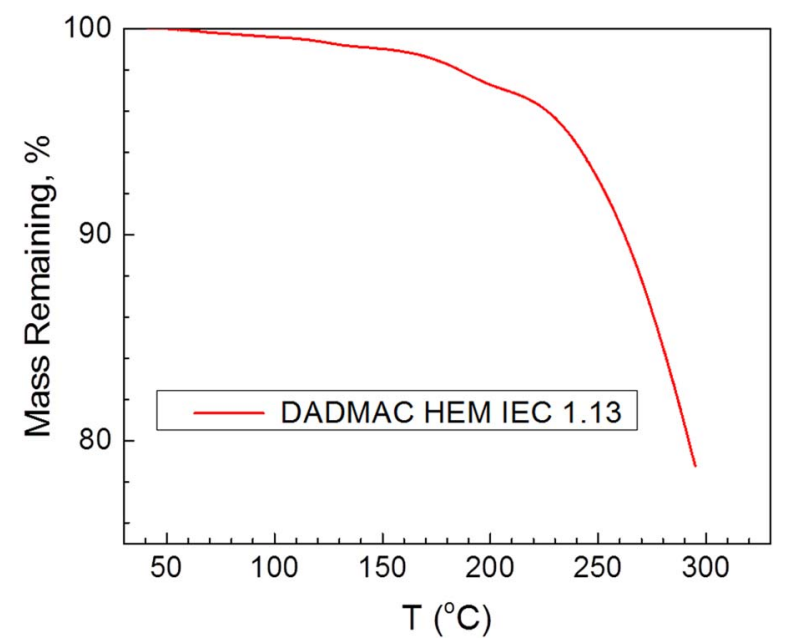

Figure 6. TGA showing thermal stability of photo-crosslinked DADMAC HEM $\left(\right.$ IEC $=1.13 \mathrm{meq} / \mathrm{g}_{\text {dry }}$ ). Membranes were measured in hydroxide form after drying for 24 hours to remove water prior to testing. 
Table II. Comparison between DADMAC HEM and photo-crosslinked anion exchange membranes in the literature.

\begin{tabular}{|c|c|c|c|c|c|}
\hline $\begin{array}{l}\text { Comonomer or } \\
\text { Copolymer system }^{\mathrm{a}}\end{array}$ & Cation $^{\mathrm{b}}$ & $\begin{array}{c}\text { IEC } \\
(\mathrm{meq} / \mathrm{g})^{\mathrm{c}}\end{array}$ & WU (\%) & $\begin{array}{l}\text { OH- Conductivity } \\
(\mathrm{mS} / \mathrm{cm})^{\mathrm{d}}\end{array}$ & $\begin{array}{l}\text { Irradiation } \\
\text { Time (min) }\end{array}$ \\
\hline $\begin{array}{l}\text { 1. Styrene, } \\
\text { Acrylonitrile, DVB }{ }^{4}\end{array}$ & VMIm & 1.18 & 116.4 & $30.8\left(30^{\circ} \mathrm{C}\right)$ & 30 \\
\hline $\begin{array}{l}\text { 2. Styrene, } \\
\text { Acrylonitrile, DVB }{ }^{5}\end{array}$ & DMVIm & 1.15 & 49.6 & $13\left(30^{\circ} \mathrm{C}\right)$ & $\mathrm{n} / \mathrm{a}^{\mathrm{e}}$ \\
\hline $\begin{array}{l}\text { 3. Styrene, } \\
\text { Acrylonitrile, DVB }\end{array}$ & MVBIm & 1.58 & 86.4 & $11\left(30^{\circ} \mathrm{C}\right)$ & 30 \\
\hline $\begin{array}{l}\text { 4. Styrene, } \\
\text { Acrylonitrile, DVB }\end{array}$ & TMVPMA & 1.62 & 92.6 & $11\left(30^{\circ} \mathrm{C}\right)$ & 30 \\
\hline $\begin{array}{l}\text { 5. Styrene, } \\
\text { Acrylonitrile, DVB }{ }^{7}\end{array}$ & EMPy & 1.41 & 87.1 & $12.7\left(30^{\circ} \mathrm{C}\right)$ & 40 \\
\hline $\begin{array}{l}\text { 6. Styrene, } \\
\text { Acrylonitrile }^{8}\end{array}$ & DAMIm & 1.22 & 95.8 & $11.3\left(30^{\circ} \mathrm{C}\right)$ & 30 \\
\hline $\begin{array}{l}\text { 7. Poly(EAGE), } \\
\text { HDT }^{12}\end{array}$ & $\begin{array}{c}\text { DABCO, } \\
\text { Quinuclidine }\end{array}$ & 1.3 & 40.5 & $2.5\left(20^{\circ} \mathrm{C}\right)$ & $\mathrm{n} / \mathrm{a}^{\mathrm{e}}$ \\
\hline $\begin{array}{l}\text { 8. Poly(EAGE), BDT } \\
\text { or } \mathrm{HDT}^{13}\end{array}$ & $\begin{array}{l}\text { DABCO, } \\
\text { Quinuclidine }\end{array}$ & 1.3 & $\mathrm{n} / \mathrm{a}^{\mathrm{e}}$ & $<1\left(25^{\circ} \mathrm{C}\right)$ & $\mathrm{n} / \mathrm{a}^{\mathrm{e}}$ \\
\hline $\begin{array}{l}\text { 9. Polyisoprene, } \\
\text { DDT }^{14}\end{array}$ & VBTMA & $0.9,1.5$ & 62.0 & $11.8\left(50^{\circ} \mathrm{C}, \mathrm{Cl}\right.$ form $)$ & $\mathrm{n} / \mathrm{a}^{\mathrm{e}}$ \\
\hline 10. TATATO, HDT & DADMA & 1.13 & 39.9 & $7.4\left(25^{\circ} \mathrm{C}\right)$ & 1 \\
\hline
\end{tabular}

${ }^{a}$ Abbreviations for comonomers and polymer precursors: $D V B$ : Divinylbenzene, Poly $(E A G E)=$ Poly(epichlohydrin-allyl glycidyl ether), $H D T=$ Hexanedithiol, $B D T=$ Butanedithiol, $D D T=$ Decanedithiol.

b Abbreviations for cationic group: VMIm = 1-vinyl-3-methylimidazolium, DMVIm = 1,2-dimethyl-3-(4-vinylbenzyl) imidazolium, MVBIm = 1-methyl3-(4-vinylbenzyl)imidazolium, TMVPMA = N,N,N-trimethyl-1-(4-vinylphenyl) methanaminium, EMPy $=\mathrm{N}$-ethyl-N-methylpyrrolidinium, DAMIm $=$ 1,3-diallyl-2-methylimidazolium, $D A B C O=1,4$-diazabicyclo-[2,2,2]-octane, $V B T M A=$ Vinylbenzyl trimethylammonium, $D A D M A=$ Diallyldimethylammonium.

${ }^{\mathrm{c}}$ All ion exchange capacities were measured by the standard back-titration approach.

${ }^{\mathrm{d}}$ Conductivity of all membranes were measured in hydroxide form and treated with $1 \mathrm{M} \mathrm{KOH}$.

${ }^{\mathrm{e}}$ Not reported

which typically produces a homogeneous polymer network. In contrast, chain-growth polymerization reactions typically form more heterogeneous networks since the evolution of molecular weight is spatially heterogeneous (evolving from microgel formation to reduced radical mobility). ${ }^{26}$ Chain-growth reactions often fall short of reaching full conversion of the vinyl functional groups owing to transport limitations (e.g., vitrification). ${ }^{16}$ This fundamental difference between these reaction mechanisms is expected to lead to drastically different HEM microstructures, resulting in the HEM property differences shown in Table II. In particular, HEM synthesized via the thiol-ene reaction (entries 7-10) generally exhibited lower water uptakes under shorter photo-polymerization times than the chain-growth polymerized HEM (entries 1-6). The DADMAC-based HEM characterized in this work reached a low water uptake of $39.9 \%$ despite only 1 minute of irradiation. The hydroxide conductivities at similar IECs for all photo-crosslinked HEMs in the literature have also been reported. It is unknown how the differences in the presumed heterogeneous membrane microstructure, membrane processing, or chemical structure contribute to the reported differences in hydroxide conductivity. Nevertheless, consideration of other charged monomers and further tuning of the photo-polymerized monomer formulation should enable insights to this understanding.

Photo-crosslinked ionomer in a catalyst layer- - A significant advantage of our single-step photo-polymerization scheme is the ability to readily incorporate additional fillers in the crosslinked polymer matrix. Previous work using spray casting of linear polymer and subsequent chemical crosslinking on top of commercial carbon paper demonstrated excellent durability of this critical conductive layer within a membrane electrode assembly (MEA). ${ }^{27}$ A photopolymerized crosslinkable monomer that is capable of crosslinking in the presence of catalyst would be a promising route to increase the catalyst layer durability. To our knowledge, the use of single-step direct photo-polymerization to create a durable catalyst layer has not been demonstrated.
Catalyst layers with Vulcan XC-72 carbon black particles were prepared by photo-polymerization as previously described. Figure 7a shows a catalyst layer with a thickness of $130 \mu \mathrm{m}$ (in the chloride form) and an IEC of $1.13 \mathrm{meq} / \mathrm{g}_{\mathrm{dry}}$. The catalyst layer after immersion in methanol for 10 days is shown in Figure $7 \mathrm{~b}$ and exhibited minimal swelling and thus excellent stability in methanol. For comparison, the catalyst layer prepared from Tokuyama AS-4 ionomer (see Figure 7c) broke down after 90 seconds of immersion in methanol (see Figure 7d). The catalyst particles in the crosslinked membrane are effectively trapped within the polymer matrix, demonstrating the advantage of
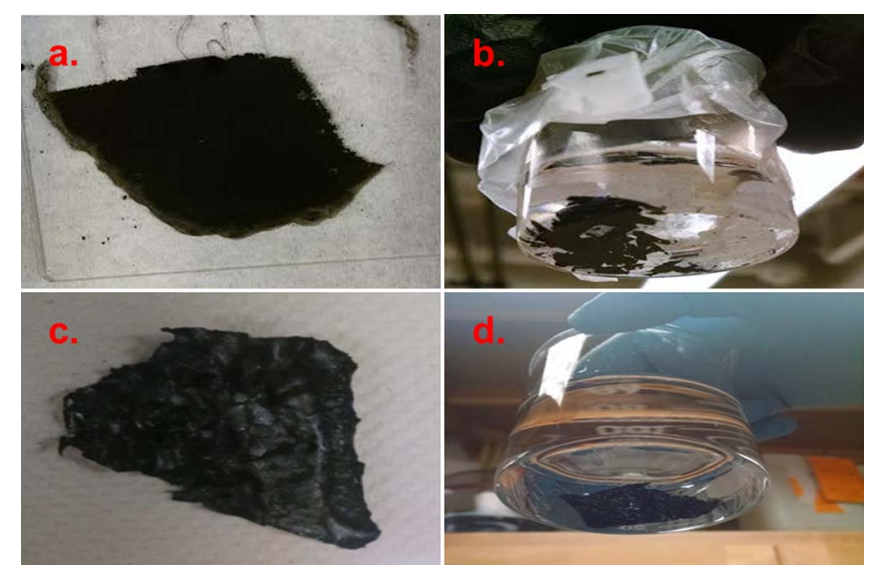

Figure 7. Photographs of DADMAC-based catalyst layer and Tokuyama AS4 (both cast from DMSO with Vulcan XC-72) before and after immersion in methanol. (a) $120 \mu \mathrm{m}$ DADMAC catalyst layer in chloride form prior to methanol immersion. (b) DADMAC catalyst layer after 1.5 weeks immersion in pure methanol solution. (c) Tokuyama AS-4 based catalyst layer prior to methanol immersion. (d) Tokuyama AS-4 based catalyst layer dissolution after 1.5 minutes immersion in pure methanol solution. 

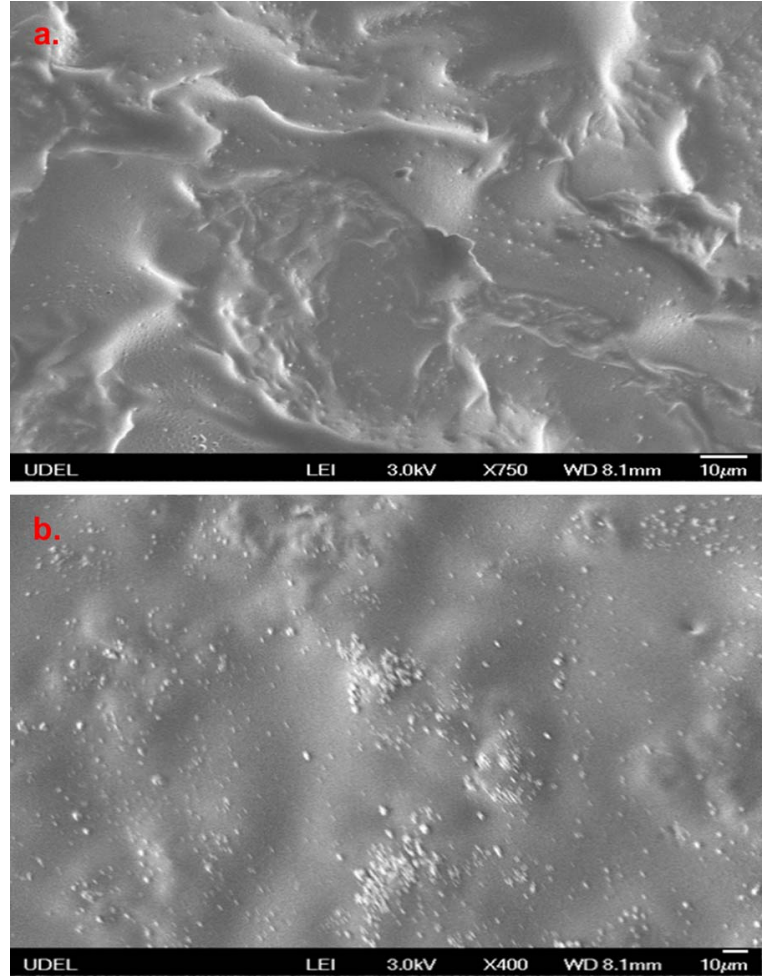

Figure 8. SEM images of DADMAC-based catalyst layer (cast from DMSO with Vulcan XC-72 carbon black) in chloride form. (a) SEM image of model DADMAC catalyst layer prior to methanol immersion demonstrating rough surface and homogeneous dispersion of nanoparticles. (b) SEM image of model DADMAC catalyst layer after 1.5 weeks immersion in methanol demonstrating a smoother surface and homogeneous dispersion of nanoparticles.

crosslinked catalyst layers. The homogeneous morphologies of the model catalyst layers were also confirmed by SEM before and after methanol immersion (see Figures $8 \mathrm{a}$ and $8 \mathrm{~b}$ ).

\section{Conclusions}

Thiol-ene chemistry has been used to produce fully crosslinked HEMs in a single polymerization and crosslinking reaction step. Through the use of the one pot membrane synthesis scheme, precise control is achieved over important membrane parameters including IEC and crosslink density. While the hydroxide conductivities obtained and chemical stability still need improvement to be sufficient for HEMFC application, the flexibility of this processing method shows promise for future development of membranes with greatly enhanced properties. This simple processing method has the potential to simplify and accelerate the fabrication of not only HEMs, but also durable catalyst layers for direct alcohol fuel cells. Future work will focus on exploring the incorporation of different monomers which may be used to develop a fundamental understanding of structure-property relationships for further enhancing membrane hydroxide conductivity and minimizing alcohol permeability.

\section{Acknowledgments}

The authors thank the National Science Foundation for financial support under the NSF CBET grant award number 1264503. Furthermore, the authors thank the W. M. Keck Electron Microscopy Facility at the University of Delaware for their assistance in SEM and EDX and Shuang Gu of the University of Delaware for his insightful discussions.

\section{References}

1. S. Gottesfeld, D. Dekel, Z. Gottesfeld, and S. D. Simakov. Google Patents, 2012.

2. J. R. Varcoe and R. C. T. Slade, Fuel Cells, 5(2), 187 (2005)

3. J. J. Wang, G. H. He, X. M. Wu, X. M. Yan, Y. P. Zhang, Y. D. Wang, and L. Du, J Membrane Sci, 459, 86 (2014).

4. B. C. Lin, L. H. Qiu, J. M. Lu, and F. Yan, Chem Mater, 22(24), 6718 (2010)

5. B. C. Lin, H. L. Dong, Y. Y. Li, Z. H. Si, F. L. Gu, and F. Yan, Chem Mater, 25(9), $1858(2013)$

6. B. Qiu, B. C. Lin, L. H. Qiu, and F. Yan, J Mater Chem, 22(3), 1040 (2012)

7. F. L. Gu, H. L. Dong, Y. Y. Li, Z. Sun, and F. Yan, Macromolecules, 47(19), 6740 (2014).

8. B. C. Lin, F. Q. Chu, Y. R. Ren, B. P. Jia, N. Y. Yuan, H. Shang, T. Y. Feng, Y. Y. Zhu, and J. N. Ding, J Power Sources, 266, 186 (2014).

9. C. R. Yang, S. L. Wang, L. H. Jiang, J. B. Hu, W. J. Ma, and G. Q. Sun, Int J Hydrogen Energ, 40(5), 2363 (2015).

10. T. J. Clark, N. J. Robertson, H. A. Kostalik, E. B. Lobkovsky, P. F. Mutolo, H. D. Abruna, and G. W. Coates, J Am Chem Soc, 131(36), 12888-+ (2009).

11. N. J. Robertson, H. A. Kostalik, T. J. Clark, P. F. Mutolo, H. D. Abruna, and G. W. Coates, J Am Chem Soc, 132(10), 3400 (2010).

12. D. Stoica, L. Ogier, L. Akrour, F. Alloin, and J. F. Fauvarque, Electrochim Acta, 53(4), 1596 (2007).

13. C. Sollogoub, A. Guinault, C. Bonnebat, M. Bennjima, L. Akrour, J. F. Fauvarque, and L. Ogier, J Membrane Sci, 335(1-2), 37 (2009).

14. M. A. Vandiver, B. R. Caire, S. P. Ertem, T. H. Tsai, E. B. Coughlin, A. M. Herring, and M. W. Liberatore, J Electrochem Soc, 162(4), H206 (2015).

15. C. E. Hoyle, A. B. Lowe, and C. N. Bowman, Chem Soc Rev, 39(4), 1355 (2010).

16. C. E. Hoyle and C. N. Bowman, Angew Chem Int Edit, 49(9), 1540 (2010).

17. Q. Li, H. Zhou, and C. E. Hoyle, Polymer, 50(10), 2237 (2009).

18. X. M. Yan, S. Gu, G. H. He, X. M. Wu, and J. Benziger, J Power Sources, 250, 90 (2014).

19. C. A. Dai, C. P. Liu, Y. H. Lee, C. J. Chang, C. Y. Chao, and Y. Y. Cheng, J Power Sources, 177(2), 262 (2008).

20. J. Coates, Encyclopedia of Analytical Chemistry, 10815 (2000).

21. P. J. Flory and J. Rehner, J Chem Phys, 11(11), 512 (1943).

22. G. Merle, M. Wessling, and K. Nijmeijer, J Membrane Sci, 377(1-2), 1 (2011).

23. M. L. Disabb-Miller, Y. P. Zha, A. J. DeCarlo, M. Pawar, G. N. Tew, and M. A. Hickner, Macromolecules, 46(23), 9279 (2013).

24. Q. J. Duan, S. H. Ge, and C. Y. Wang, J Power Sources, 243, 773 (2013).

25. E. Antolini and E. R. Gonzalez, J Power Sources, 195(11), 3431 (2010).

26. C. N. Bowman and C. J. Kloxin, Aiche J, 54(11), 2775 (2008).

27. J. R. Varcoe, R. C. T. Slade, and E. Lam How Yee, Chem Commun, (13), 1428 (2006). 